\title{
The development of the Schema-Action-World (SAW) taxonomy for understanding decision making in aeronautical critical incidents
}

\begin{abstract}
The perceptual cycle model (PCM) offers a process-orientated approach to understanding decision making. This approach is distributed in nature as it considers how internally held schemata and external environmental information interact to produce actions and behaviour. This an essential component of any incident reporting system, al though it is often lacking. In its current form the PCM only provides a very high-level of explanation. This research utilised data from critical decision making interviews to deconstruct the three high-level categories of the PCM into a 28 item taxonomy. In doing so, we were able to provide a more detailed description of aeronautical critical decision making (ACDM) by demonstrating the relevance of different concepts in different phases of dealing with an incident. The data were used to model the ACDM process. The taxonomy can be used for gaining a comprehensive understanding of both the contextual and cognitive components of decision making, something that existing taxonomiesand models often fail to do.
\end{abstract}

Keywords: incidents, taxonomy, perceptual cycle model, aeronautical critical decision making, qualitative analysis

\section{Highlights}

- This paper develops a 28-item taxonomy based on the perceptual cycle model

- Analysis of twenty critical incident interviews demonstrated the importance of different factors at different phases of dealing with an incident

- The taxonomy can be used to explore pilots' decision making processes and has application to how incidents are reported and analysed.

\section{Introduction}

\subsection{Incidents and accidents in the aviation domain}

Incidents occur when all available safeguards are defeated and there is a move away from normal system behaviour without sustaining any losses (Cooke and Rohleder, 2006; Griffin et al., 2015). Fortunately, aviation accidents are rare and the nature of them means that firsthand accounts are difficult to obtain. It is acknowledged that incidents are the precursors to accidents and occur more often (Weigmann and von Thaden, 2003). Griffin et al. (2015) argued that non-accident scenarios can be used to understand the aviation system better and should be considered as 'free lessons'. In doing so, incidents should be treated as accidents in terms of the effort of investigation that goes into them, especially in light of falling accident numbers. Griffin et al. (2015) argued that this approach has the potential to overcome the barrier of hindsight; individuals are available to be questioned about reasons for their actions and assessments. In particular, incident reporting systems are highlighted as areas to capitalise on because incidents cover a huge range of scenarios, thus generate a lot of information for safety development. Similarly, Cooke and Rohleder (2006) advocated 'incident learning systems' to be in place within organisations in order that useful information can be extracted from events and used to improve performance. In the UK aviation domain, the Civil Aviation Authority's Confidential Human Factors Incident Reporting (CHIRP) System is an attempt to 
do this. It is provides amalgamated data from voluntary and mandatory reporting procedures for incidents and accidents.

O'Hare (2006) was interested in whether there were differences between accidents and incidents in terms of flight crew performance, or whether it was merely a matter of luck. He found differences between accident- and incident-involved pilots in terms of age, flight experience, and involvement in hazardous events. Furthermore, incidents were more likely to be attributed to failures to detect or diagnose information, whereas accidents were more likely to be attributed to failures to choose an appropriate goal or strategy. This highlights the importance of learning as much as possible from incidents. However, incident reporting systems will only be as good as the interpretation made of the data. For example, Beaubien and Baker (2002) argued that the introduction of the Aviation Safety Action Program (ASAP) had the potential to provide carriers with a powerful tool for understanding human factors issues because it was designed to collect information about why something happened, rather than just what happened. The tool, however, was not used to its fullest potential owing to the fact that ASAP collects text narratives that require costly and time-consuming content analysis. Wiegmann and von Thaden's (2003) developed the Critical Event Reporting Tool (CERT) as an attempt to improve pilot's reporting of incidents. CERT was designed to serve as a knowledge elicitation tool that pilots could use for recalling event-related information. It uses schematic organisers to encourage pilots to think of why an incident happened in addition to describing what events occurred during an incident. It was found that reports written by pilots who used CERT contained more analytical statements about why things had occurred during the incident than reports by pilots who did not use CERT. Similar results were reported by O'Hare (2006), leading to the conclusion that structured probing with relevant categories produces better incident reports. Sarter and Alexander (2000) argued that incidents are often not reported in psychological terms of 'why', but rather at the descriptive 'what' level. Using a consistent classification scheme can be one way to improve data interpretation, the next section discusses the importance of classification taxonomies in relation to Ergonomics research.

\subsection{The role and utility of taxonomies in Ergonomics research}

Taxonomy is the science of defining groups, traditionally biological organisms, on the basis of shared characteristics and giving names to those groups. The primary purpose of classification is to describe relationships of the constitute elements in regard to each other and to similar elements, and to simplify these relationships so that general statements can be made about classes of elements (Fleishman and Quaintance, 1984). Developing and utilising taxonomies to assist research efforts can have a number of advantages, including the facilitation of efficient and accurate data collection and analysis, establishing common terminologies that can be employed by a variety of researchers, and they are associated with practical benefits such as training design and performance measurement (Moir et al., 2003; Fleishman and Quaintance, 1984). Taxonomies can be used in two main ways; some researchers choose to develop a bespoke taxonomy for the domain in question and examples of this include a gliding accident analysis taxonomy developed by Jarvis and Harris (2010) and a construction work taxonomy developed by Moir et al. (2003). Alternatively, a preexisting taxonomy can be applied to relevant data. This approach was taken by Stanton and Salmon (2009) who applied well established taxonomies of human error to develop an understanding of automotive driver errors.

In Ergonomics research taxonomies can be used for a variety of purposes including classifying behaviour of individuals or teams, predicting risk with error taxonomies and for accident analysis purposes. As acknowledged by Salmon et al. (2012), accidents and accident causation are central themes in global Ergonomics research efforts. The methods used to investigate and analyse accidents are critical in aiding understanding of underlying causes and indicating areas for systemic improvements. Taxonomies have been widely applied for this purpose, particularly in aviation (for comprehensive reviews see O'Hare (2000) and Jarvis and Harris (2010)) which led Griffin et al. (2010) to affirm that taxonomic accident models are greater in number than any other. In this paper, a bespoke, data-driven, perceptual cycle 
taxonomy was developed and is presented in the context of decision making. Fleishman and Quaintance (1984) argued that a comprehensive taxonomy should focus on human and environmental dimensions, rather than just one or the other, as this allows the impact of each on the other to be understood. This is especially relevant to understanding aviation incidents where previous criticisms have come from the fact that a descriptive explanation of what happened, ignores the psychological element of why it happened (Sarter and Alexander, 2000). The Perceptual Cycle Model (PCM) is now presented as an approach that encompasses both environmental and psychological components, and therefore we argue that it has potential utility in enhancing the explanation of incidents.

\subsection{The Perceptual Cycle Model as a process oriented approach}

Aviation epitomises the Naturalistic Decision Making paradigm (NDM; Klein et al., 1989) because it is an environment in which experts make rapid decisions with available information, in time critical situations and that can have negative payoffs. Decision judgement errors are often a significant contributory factor in incidents and accidents, with some arguing that they are the primary factor in over $50 \%$ of general aviation accidents (Simpson, 2001). For example, O’Hare et al. (1994) found that 63\% of fatal and serious aviation accidents in their dataset were characterised by decision errors. Decision making research presents an interesting field of enquiry because there is often no clear standard of correctness and there can be a loose coupling between event outcome and decision process (Orasanu and Martin, 1998). The decision maker acts according to their understanding of the situation at the time, a principle that has been termed local rationality (Reason, 1990; Dekker, 2011). Errors can therefore arise because of deficiencies in the decision makers' knowledge base or in the process of reaching a decision. As such, it is essential to understand why the actions and assessments undertaken by a decision maker made sense to them at the time (Dekker, 2006). In the highly automated aviation environment more procedural and predictable tasks are handled by machines, whilst humans are left responsible for tasks that require diagnoses, judgement, and decision making (Militello and Hutton, 1998). As such, it is more pertinent than ever to undercover the decision making process that humans engage in. We propose that Neisser's (1976) PCM provides a process-oriented approach to understand decision making. The PCM, depicted in Figure 1, emphasises the role that both schemata (internally held mental templates) and world information play on shaping actions, including decisions. Schemata are triggered by contextual conditions and direct perception and behaviour, thus interaction in the world. The world information that is experienced can have a modifying and updating effect on cognitive schemata, thus influencing further interaction. This individual model of information processing recognises that cognition is extended beyond the individual because behaviours are grounded within the context of the environment in which they occurred. As such, it offers a useful framework for explaining the mechanisms involved in decision-making and, in turn, the influence on incidents (Plant and Stanton, 2012a; 2013a). 


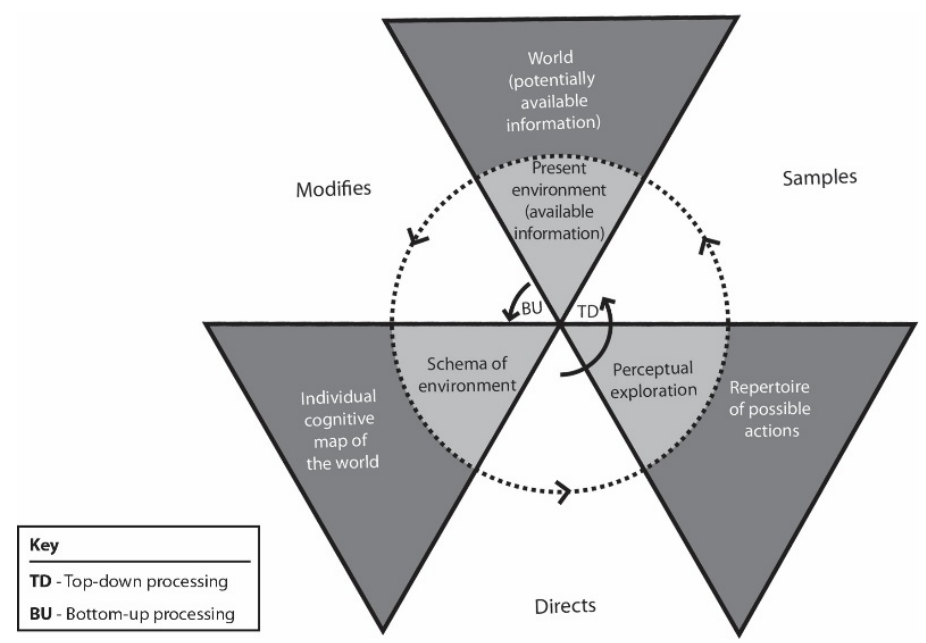

Figure 1. The Perceptual Cycle Model

The model has been most widely applied as an explanatory framework to understand factors such as situational awareness or decision-making from the perspective of individuals operating as part of larger systems. For example, in the aviation domain Plant and Stanton (2012a) demonstrated how the PCM could explain the erroneous actions of the pilot's involved in the Kegworth aircraft accident. Similarly, this approach has been used in the railway domain (see Stanton and Walker, 2011 and Salmon et al. 2013). Whilst the domains of application and methodological approaches vary, there are two distinct commonalities. Firstly, the research has usually occurred in situations where data are derived from accident reports in which first-hand accounts of incidents are not available (Salmon et al., 2013). Therefore, it is essential that the explanation of decision-making (or any element of behaviour) provided by the PCM is as accurate and detailed as possible because it is used to propose valid explanations of behaviour. Secondly, the research efforts have attempted to understand how the three components of the model interacted during the scenario under investigation (i.e. what schemata were held by the operators, what environmental information they were exposed to and how these factors interacted to produce their actions within the context of their operating environment). However, to our mind, one of the biggest limitations of the PCM is that in its current form it offers only a very high level of descriptive detail, comprising only the three categories of: schema, action and world. Overcoming this issue is one of the key aims of this research and will be achieved through the development of an extended PCM taxonomy.

\subsection{Objectives}

The motivation for this paper was to build on previous research (e.g. Plant and Stanton, 2013a; 2014a) and continue to develop the utility of Neisser's (1976) PCM as an explanatory tool to aid our understanding of decision making during critical incidents. The primary objective of this research is to provide detailed descriptions of the three categories of the PCM in order for it to deliver a more complete understanding of the decision making process. This is achieved by the development of the Schema-ActionWorld (SAW) taxonomy, using data from twenty decision making interviews. This was then used to model the process of Aeronautical Critical Decision Making (ACDM).

\section{Method}

\subsection{Data collection}

Twenty helicopter pilots were interviewed using the Critical Decision Method (CDM; Klein et al., 1989). This is one of the most commonly used cognitive task analysis methods and achieves knowledge elicitation through the use of cognitive probes as a tool for reflecting on 
strategies and reasons for decisions during non-routine situations (Stanton et al., 2013). The CDM procedure involves participants describing a critical incident they were involved with, defining a timeline of events and answering the deepening probes. The deepening probes cover factors such as key goals, the role of experience, decisions that were made, options available and key sources of information. For a more detailed description of the procedure and an evaluation of the method readers are directed to: Crandall et al. (2006), Klein and Armstrong (2005), Stanton et al. (2013) and Plant and Stanton (2013a). The benefit of the $\mathrm{CDM}$ is that the retrospective nature of the method means that the events of interest have occurred so there is no need to create artificial simulations that are limited in contextual richness, nor is there a need to wait for non-routine events to occur (Klein et al., 1989). Furthermore, the semi-structured nature of the interview results in less time to gather relevant information, but retains the freedom to explore interesting data. The standardised probes also result in more reliable data (Plant and Stanton, 2013a).

The twenty pilots that participated in the study were recruited through an advert placed on the British Helicopter Associate website and via word-of-mouth. The sample consisted of 19 males and 1 female. Twenty five percent of the sample were aged between 3140 years, forty percent were aged between $41-50$ years and thirty five percent were aged between 51-60 years. The pilots were all relatively experienced; flying hours ranged from 1150-13000 $($ mean $=5942, \mathrm{SD}=3304$, median $=5000)$. The pilots were employed in a variety of occupations including Search and Rescue $(n=2)$, military $(n=8)$, personal passenger transport $(n=5)$, North Sea transport $(n=2)$, test pilots $(n=2)$, and police $(n=1)$. This study was granted ethical permission by the University of Southampton Research Ethics Committee (Id: CEE 201011-02).

Each pilot was interviewed at their place of work and was asked to think of a critical incident they had been involved with, which was defined as being a non-routine or unexpected event that was highly challenging and involved a high workload in which you were the primary decision maker (Klein \& Armstrong, 2005). Each participant provided a highlevel overview of the incident and structured a timeline of events. After the incident description/timeline construction phase, the cognitive probes were asked in relation to the decision making during the incident. The interviews were audio recorded and later transcribed.

\subsection{Data analysis}

\subsubsection{Data treatment}

The twenty CDM interviews produced data about critical incidents around a range of situations including technological malfunction, environmental conditions, spurious warnings human error, and operational incident. The data from each interview were structured into six generic phases of incident that have been previously identified in similar data (Plant and Stanton, 2012b). The six phases were (including percentage of data in each phase): (1) preincident (9\%), (2) onset of problem (23\%), (3) immediate actions (24\%), (4) decision making (24\%), (5) subsequent actions (15\%) and (6) incident containment (5\%). In accordance with the guidelines on qualitative data analysis the text was chunked into meaningful segments of approximately one sentence or less in length. This resulted in 904 text segments across the twenty interviews. The data analysis techniques undertaken here are based on the principles of thematic analysis which is a method for identifying, analysing and reporting patterns (themes) within data (Braun \& Clarke, 2006). This approach offers a flexible and useful research tool that can provide a detailed account of complex data (Braun and Clarke, 2006). The data were subjected to both deductive and inductive thematic analysis. Figure 2 provides a flowchart to summarise the data analysis process.

\subsubsection{Deductive thematic analysis}

Braun and Clarke (2006) argued that there is not one ideal theoretical framework or method for conducting qualitative analysis, but what is important is that the framework or method matches the researcher's focus of investigation. Here, deductive thematic analysis was initially used to classify the data. In this process themes or patterns in the data are generated 
from existing theory (Boyatzis, 1998). In accordance with the broader research question of exploring decision making processes from the perspective of the perceptual cycle, the PCM was used as the theoretical underpinning for the deductive thematic analysis. As such, three themes were defined as: schema (statements relating to the use of prior knowledge and knowing things because of experience or expectations), action (statements of doing an action or discussing potential actions that could be taken) and world (statements relating to potential or actually available information in the world including physical things, conditions or states of being). Interested readers are directed to Plant and Stanton (2013a) which describes the development of the coding scheme in more detail. As described in the introduction, these three high level themes are based on the categories of the PCM. The focus of this paper is not to look at the these themes in any detail because this has been done previously (see Plant \& Stanton, 2012a; 2013; 2014) but rather to explore themes within these high level categories via inductive thematic analysis.

\subsubsection{Inductive thematic analysis}

Inductive thematic analysis was undertaken on the data in each of three high level categories of schema, action and world in order to uncover more detailed themes within this data. Inductive thematic analysis is the process by which the data are used to generate themes (Patton, 1990). In its purest form inductive analysis is a process of coding data without trying to fit it into a pre-existing coding frame (Braun \& Clarke, 2006). However, the data in this study were already classified into the three PCM codes and this therefore had some bearing on the nature of the themes generated in the inductive analysis process. An advantage of thematic analysis is the flexibility of the method which allows themes to be determined in a number of ways, Braun and Clarke (2006) stressed the importance of being consistent with the analysis when generating themes. Here, the constant comparison technique was employed whereby each text segment was compared with previous items to see whether the same or a different phenomenon was described. Furthermore, the text segments were exclusively coded meaning that only one theme could be applied to one text segment. If a text segment represented more than one theme the segment was split up accordingly (e.g. if two different types of action were described in one segment), but this did not affect the high level coding. The taxonomy was developed through an iterative process of review and refinement using the opinions and expertise of colleagues in the research group. The process of inductive analysis resulted in the identification of six schema-subtypes, 11 action-subtypes and 11 worldsubtypes. These are presented in the SAW taxonomy in Section 3.1.

\subsubsection{Calculating importance of SAW concepts using sociometric status}

Aside from providing a more detailed explanation of the PCM, the relationships between different elements of the perceptual cycle were explored. To do this, for each CDM interview, each assigned code (given to the text segment) was collated into a frequency table that captured 'from-to' links between the different categories as they appeared in the coded transcripts. For example, a text segment coded as 'action_decision action' (from), followed by a segment coded as 'world_standard operating procedure' (to) was recorded in the frequency matrix. This was summed across the twenty interviews to create an amalgamated frequency count for each of the six phases and across the data set as a whole. This frequency count analysis was subjected to network analysis using the Agna ${ }^{\mathrm{TM}}$ software. This is a social network analysis tool but is becoming an increasingly popular method for general network analysis. Walker et al. (2010) argued that it is particularly compatible with the distributed cognition because it focuses on relationships among operators embedded in their work context. It provides a range of different metrics for analysing networks and interested readers are directed to other texts for comprehensive descriptions of available metrics, including: Houghton et al., (2006); Baber et al., (2013) and Stanton (2014).

Specifically, we were interested in the metric of sociometric status to define key information elements related to critical decision making. Sociometric status refers to the relative importance of a node (concept) within a network as its calculation is based on the connectedness (i.e. number of connections to other nodes) of a particular information element. 
The argument is that concepts with high sociometric status values represent key concepts as they are highly connected to other concepts within the critical decision making network (Salmon et al., 2014; Stanton, 2014). Here, the concepts (i.e. PCM subcategories) with a sociometric status value above the mean plus one standard deviation for the network were identified as primary concepts, those with a value higher than the mean but lower than the mean plus one standard deviation were identified as secondary concepts and those with a value lower than the mean were identified as tertiary concepts. The network analysis also enabled a PCM network of critical decision making to be produced. Section 3.2 describes the results of this analysis.

\subsection{Reliability assessment}

The reliability of both coding schemes was assessed by calculating inter- and intra-rater reliability. The former being the consistency between different people coding the data and the latter being the consistency between the same person at different times coding the data. It is well acknowledged that calculating reliability is an essential component for evaluating the quality of a coding scheme or taxonomy (Fleishman and Quaintance, 1984; Burla et al., 2008). To assess reliability, three additional coders were judged by the standard set by the expert coder in a blind condition, i.e. raters were unaware of the expert's coding decisions. Reliability scores were calculated based on percentage agreement, i.e. number of agreements divided by the number of times the coding was possible, multiplied by 100 . This was in accordance with the literature that has suggested this is the most suitable way to calculate reliability scores with data of this nature (Boyatzis, 1998). There is general consensus that $80 \%$ agreement is the threshold for acceptable agreement (Lombard et al., 2002; Marques and McCall, 2005) and this is used as the benchmark here for assessing reliability. Plant and Stanton (2014a) have previously evaluated the high level coding scheme. It was found that all results from the reliability assessment exceeded the $80 \%$ threshold level of agreement. Interrater reliability averaged $84 \%$ and intra-rater reliability averaged $90 \%$. Furthermore, Plant and Stanton (2013a) conducted a reliability study with twenty coders and found that agreement exceeded the $80 \%$ threshold and this was shown to be considerably higher than from chance alone.

To assess the reliability of the SAW taxonomy the coders were given a 30 minute session describing the different classification categories. The coders were presented with 200 text segments (10 from each interview) which represented $22 \%$ of the data. This process was repeated after a four week interval to assess intra-rater reliability. The text segments were selected using a random number generator. This randomly generated 10 numbers within the range of total number of text segments for each interview. The schema (87\%) and world subcategories (82\%) exceeded the $80 \%$ threshold for inter-rater reliability, and intra-rater reliability (both scoring 88\%). However, the action category only achieved $73 \%$ agreement for inter-rater reliability (82\% was achieved for intra-rater).

On close examination of the data it appeared that the subcategory in which there was most disagreement was 'mental action'. In the original coding scheme this was defined as 'statements relating to actions that are not explicitly observable, actions that occur in the mind (e.g. thinking about something or imagining how a course of events might unfold'. From the reliability assessment it was clear that this category of mental action was too ambiguous and was easily confused with other categories including decision action and concurrent diagnostics. With the collaboration of the reliability coders it was decided that 'situation assessment' would be a more appropriate classification and this was defined as 'statements relating to actions that relate to the evaluation and interpretation of available information'. All text segments relating to mental action were re-coded by the coders and were either assigned to the situation assessment category or another relevant category (e.g. concurrent diagnostics). The re-analysis of this category produced an inter-rater reliability agreement of $84 \%$, above the accepted threshold. This process of review and refinement of themes is an essential part of thematic analysis and demonstrates the benefit of conducting a rigorous reliability study as it resulted in a higher quality coding scheme. 


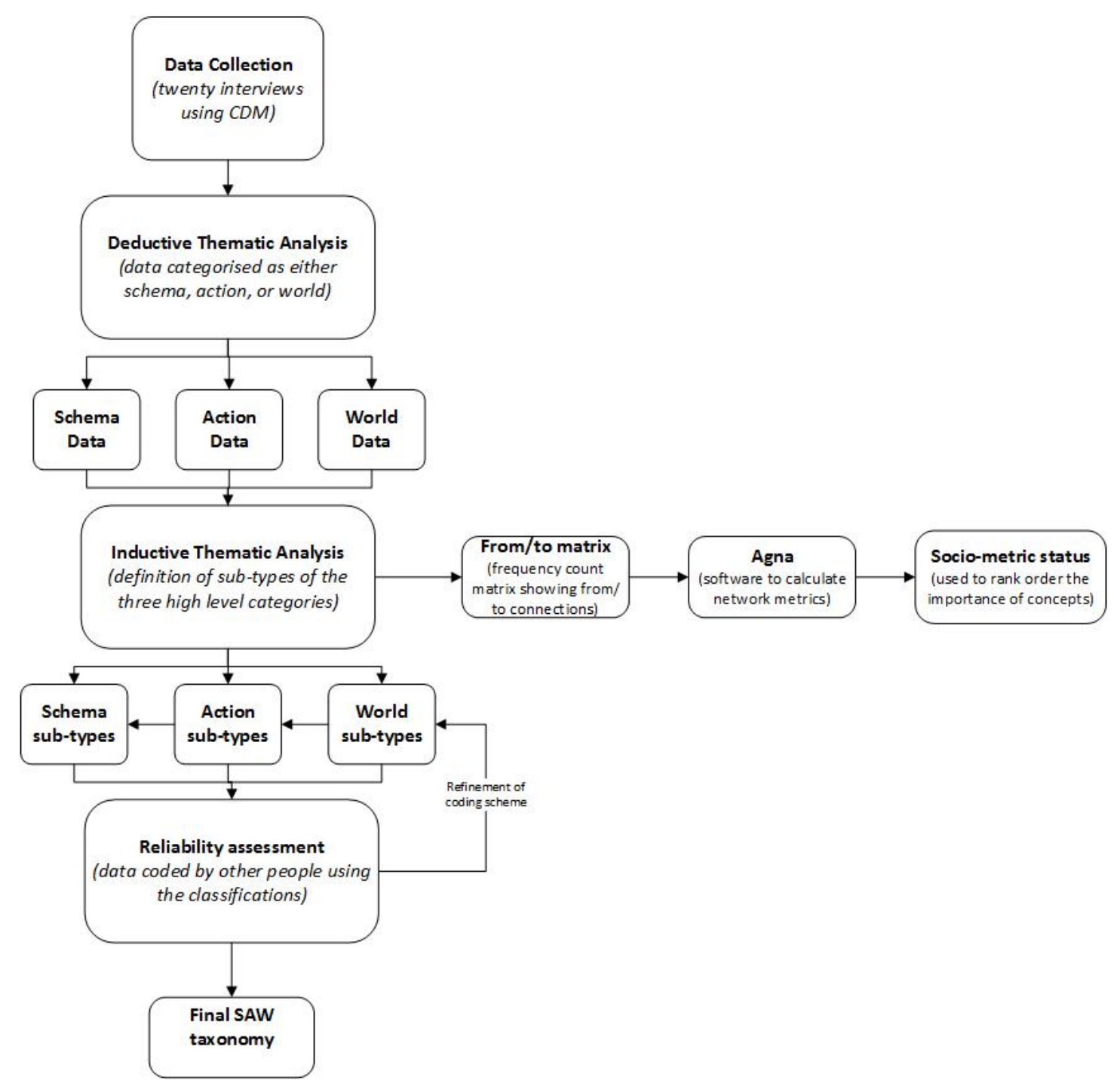

Figure 2. Flowchart summarising the data analysis process

\section{Results}

\subsection{SAW Taxonomy}

The impetus for this research was to provide a more detailed account of the high level categories of schema, action and world that are provided in Neisser's (1976) original PCM. This was achieved through a process of inductive thematic analysis to produce a data-driven taxonomy. The SAW taxonomy resulted in 28 categories: six schema-subtypes, 11 actionsubtypes and 11 world-subtypes.

\subsubsection{Schema subtypes}

Table 1 presents the six schema subtypes along with a description of the classification theme and examples from the text extracts of the CDM interviews. The six schema subtypes include: vicarious past experience, direct past experience, trained past experience, declarative schema, analogical schema and insufficient schema. Of the entire data $15 \%$ related to the overall category of schema, the breakdown of the schema data across the subtypes is also provided in Table 1 (percentages). Direct past experience, trained past experience and declarative schema are the most represented categories, accounting for $26 \%, 25 \%$ and $24 \%$ of the data respectively.

\subsubsection{Action subtypes}


Table 2 presents the 11 action subtypes that were identified through the inductive analysis process. The 11 action subtypes included: aviate, navigate, communicate, system

management, system monitoring, environment monitoring, concurrent diagnostics, decision action, situation assessment, non-action and standard operating procedure. Of the entire data set $43 \%$, was categorised as action and the breakdown of these data across the action categories is provided in Table 2 (percentages). Aviate (the action of flying the aircraft) is the most represented category (23\% of data), followed by decision action (16\%).

\subsubsection{World subtypes}

Table 3 presents the 11 world subtypes that were identified through the inductive analysis process. The 11 world subtypes included: natural environmental conditions, technological conditions, communicated information, location, artefacts, display indications, operational context, aircraft status, severity of problem, physical cues and absent information. The world category made up $42 \%$ of the total data set, the breakdown across the individual world categories is provided in Table 3 (percentages). The categories that shared the highest proportion of data were natural environmental conditions, location and operational context, each contained $14 \%$ of the world data.

*Table $1^{*}$

*Table 2*

*Table $3 *$ 


\subsection{Perceptual cycle analysis of critical decision making}

The motivation behind developing a detailed taxonomy based on the PCM is that it increases the descriptive power of the PCM in order that a more detailed understanding of how operators engage in the perceptual cycle is provided. Here, this has been explored from the perspective of ACDM. Calculating the sociometric status of each of the SAW taxonomy categories produced primary, secondary and tertiary concepts for dealing with a critical incident; this was based on data summed across the twenty CDM interviews and therefore provides a composite account. Figure 3 shows the PCM annotated by primary, secondary and tertiary concept for the whole process of dealing with a critical incident, i.e. not phase of flight specific. There were five primary concepts identified, in the action category these were aviate and decision action and in the world category these were location, natural environment and display indication. There were no primary concepts identified in the schema category. Eight secondary concepts were identified; in the action category these were system management, communicate and situation assessment, in the world category these were operational context and physical cues and in the schema category these were direct past experience, trained past experience and declarative schema. The remaining 15 concepts from the SAW taxonomy were identified as tertiary concepts.

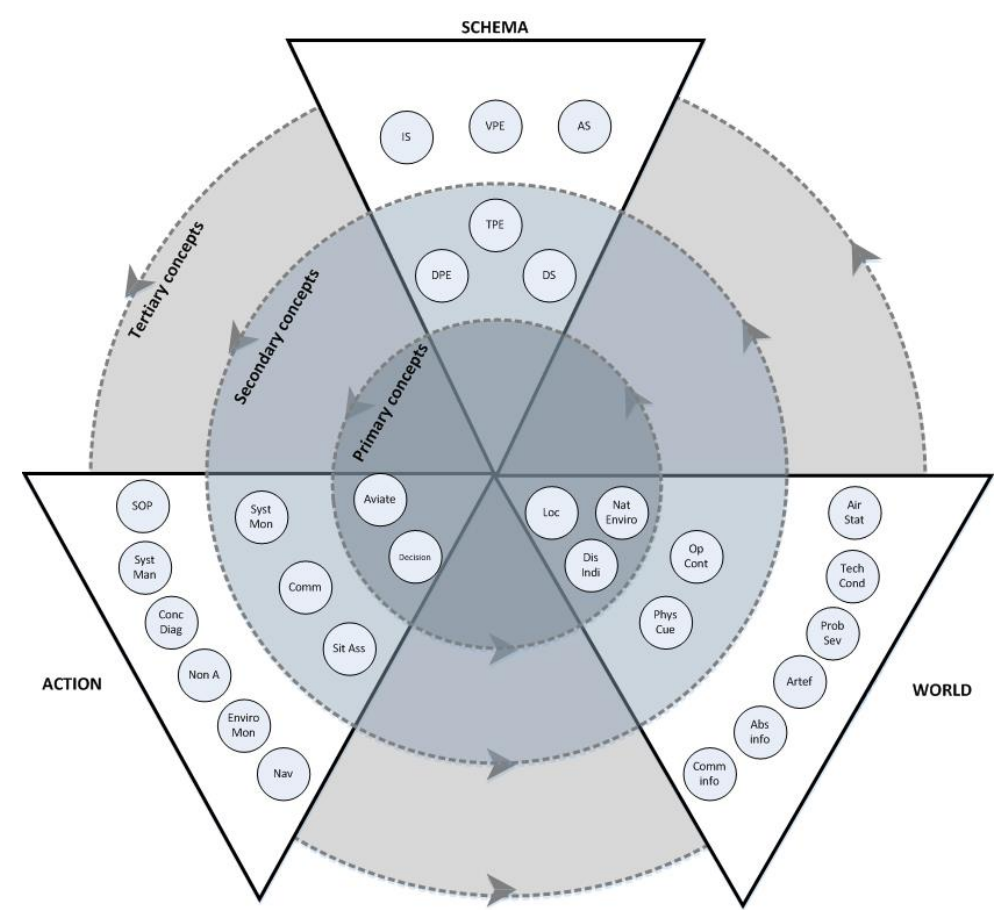

Figure 3. The primary, secondary and tertiary concepts of the PCM for dealing with a critical incident

The sociometric analysis was also conducted for each of the six phases of dealing with a critical incident the results of this are provided in Table 4 . Interested readers are also directed to Plant and Stanton (2014a) for a detailed explanation of the incident phases. Due to space constraints it is not possible to talk about every concept within each phase, so an overview based on the primary and secondary concepts is provided:

- $\quad$ Phase 1: pre-incident

In this phase the pilots set the scene and described the antecedents to the incident. The most relevant concepts in this phase generally came from the world concepts. There were two primary concepts, both subtypes of world, being natural environmental conditions and operational context. Furthermore, location and physical cues were also defined as secondary concepts. Aviate and standard operating procedures were highlighted as the most relevant action concepts and declarative schema was the most important schema concept. 
- Phase 2: Onset of problem

This phase was characterised by the primary concept of physical cue. Technological conditions and display indication follow as the second and third most relevant world concepts. In this phase the most relevant action concept and third most relevant overall concept was aviate, the act of flying the aircraft. Other important action concepts included systems monitoring, concurrent diagnostics and systems management. The most relevant schema concepts were direct past experience, trained past experience and insufficient schema.

- $\quad$ Phase 3: Immediate actions

There were no primary concepts in this phase, but the most important concept was display indication (world concept) followed by trained past experience (schema concept). Action subtypes generally dominated this phase, with seven of the 14 secondary concepts coming from the action category, including aviation, systems monitoring, concurrent diagnostics, decision action, communicate, situation assessment and standard operating procedures.

- $\quad$ Phase 4: Decision making

In this phase, unsurprisingly, decision action was the primary concept. The remaining secondary concepts were evenly spread around the three elements of the PCM, with four world concepts (location, aircraft status, absent information and display indication), four action concepts (situation assessment, communication, aviate and standard operating procedure) and three schema concepts (direct past experience, trained past experience and declarative schema).

- Phase 5: Subsequent actions

There are no primary concepts in this phase, but the top five most relevant secondary concepts are aviate, decision action, declarative schema, communicate and display indication.

- Phase 6: Incident containment

In this phase, again, there are no primary concepts and only action and world subtypes appear as secondary concepts. Including in the action category; aviate, systems management and communicate and in the world category; location, operational context and aircraft status. Eleven of the 28 concepts do not feature in this phase of the incident, given that only five per cent of the data are represented in this phase.

\section{*Table $4 *$}

Figure 4 provides the SAW model of ACDM based on the primary and secondary concepts identified in the data. The links between each concept represent the directional flow of information and the strength of the links was informed by the Agna ${ }^{\mathrm{TM}}$ network data, the thicker the line, the stronger the link is between the concepts. The analysis showed that the most important concept for ACDM was the action concept of aviate; highlighted in Figure 4 as most of the other concepts are connected to aviate in some way. This was followed by decision action and then three concepts from the world category: location, natural environmental conditions and display indications. 


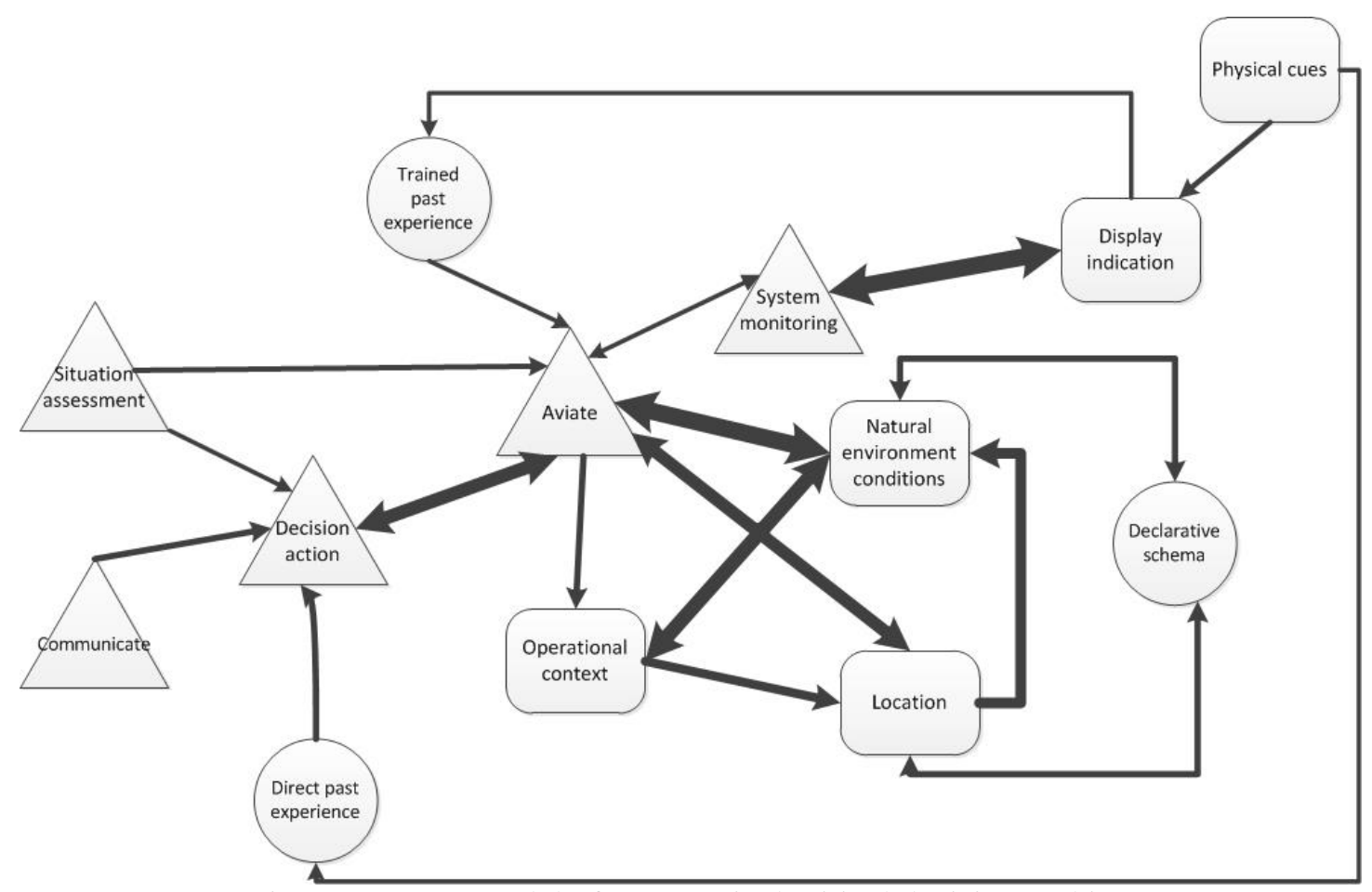

Figure 4. SAW model of aeronautical critical decision making

\section{Discussion}

Decision making can be one of the determining factors regarding whether or not normal situations turn into incidents, and incidents turn into accidents. In sociotechnical systems it is appropriate to view decision making through the perspective of distributed cognition, rather than as a process that occurs in the head of an isolated individual (Hutchins, 1995; Stanton, 2014). Neisser's (1976) PCM provides this distributed cognition perspective by acknowledging the interaction between internal cognitive schemata held by the decision makers and the external environment in which decisions are made. However, to date, the PCM has only provided a high level description of the three elements that make up the model. The impetus for this research was to decompose these three elements into more detailed subtypes in order that the explanatory power of the model is increased. In doing so we were able to provide a more comprehensive understanding of critical incident decision making.

\subsection{SAW taxonomy}

The SAW taxonomy is a 28 item classification scheme for gaining a more detailed understanding of the three high level categories of the PCM and therefore a comprehensive view of the decision making process. The taxonomy can be utilised to explore the interaction of the specific concepts during the perceptual cycle process. The development of this taxonomy was data-driven, using interview data from twenty helicopter pilots which generated over 900 text segments. Inductive thematic analysis was employed to generate the taxonomy items which were continually reviewed and refined. The resulting taxonomy consisted of six schema, 11 action, and 11 world categories. It enables researchers to classify data according to the perceptual cycle but in a much more detailed way than previously possible. The value of this is that the taxonomy considers factors that are internal to the decision maker (i.e. internal cognitive schemata) but also external factors that have the potential to influence the decision making process (i.e. external environmental information) and the actions that mediate between the two. This comprehensive taxonomy can therefore be used to explore the interaction between an operator and the world in which they work, which is essential for understanding the decision making process, rather than just the decision 
outcome and therefore has potential utility as a way of interrogating aviation incident reports. Understanding this process will lead to more detailed explanations of incidents and accidents rather than just a surface level label of 'human error' or 'bad decision making' (Dekker, 2006). As detailed in the introduction, taxonomies are often criticised for their over emphasis on descriptive 'what' information, ignoring the psychological 'why' information. The SAW taxonomy captures the three elements of the PCM: internal cognitive schema, actions undertaken and world information available, and as such can aid the understanding of the perceptual cycle process, thus capturing the 'why' element of decision making.

\subsection{Gaining perceptual cycle insights into ACDM}

As stated by Fleishman and Quaintance (1984:44) "classification is not an end in itself, rather it is a tool that provides an increased ability to interpret, predict or control some facet of performance". The SAW taxonomy was developed to gain a more detailed understanding about the process of ACDM from the perspective of the PCM. The analysis discussed is a composite account summed across the twenty interviews and is considered both as a whole and by phase of incident. In both instances the SAW concepts were scored on sociometric status to determine their relative importance (the higher the status the more important the concept). This resulted in the classification of primary, secondary and tertiary concepts (only primary and secondary concepts are discussed as these are most pertinent to the ACDM process). Figure 4 demonstrated the links between the concepts, with aviate being the concept of primary importance. This is unsurprising given that aviate is the primary task management requirement in the 'aviate-navigate-communicate-manage systems' strategy employed by all pilots when dealing with non-normal situations. It is of paramount importance that, regardless of what is happening around them, pilots continue to fly their aircraft. In a study of task management priorities, Schutte and Trujillo (1996) found that participant's prioritised 'aviate' when dealing with non-normal situations. The next most important concept was 'decision action'. This is to be expected in data collected for decision making research and increases confidence with the method for collecting decision-based data.

\subsection{Practical Applications for learning from incidents}

As described in the introduction, the usefulness of any incident reporting system will only be as good as the data interpretation that occurs. It has been consistently advocated that reporting systems and subsequent analysis need to grasp why things happened, as opposed to just what happened (Sarter \& Alexadner, 2000; Griffin et al., 2015). The SAW taxonomy has the potential to provide this level of understanding as it encompasses the interaction between the psychological components (i.e. the schema based categories), the actions undertaken, and the world information that was utilised. The manual analysis undertaken here may not be feasible with larger data sets and therefore thought needs to be given to automating the process. Text analysis software such as Leximancer ${ }^{\mathrm{TM}}$ has the potential to assist. In previous research Plant and Stanton (2011) used Leximancer ${ }^{\mathrm{TM}}$ to automatically analyse a critical incident interview and the resulting categories were similar to the categories in the SAW taxonomy.

Alternatively, the categories within the SAW taxonomy could be used to structure the free text narrative section of incident reporting systems. This is an approach taken by Beaubien and Baker (2002:4) who employed a generalised human factors taxonomy to aid the reporting process in the ASAP system. They argued that "...utilising drop down menus and check box items...carriers will easily be able to classify and quantify the root cause of pilot error". From the language used it would appear that a reductionist approach is being taken which is not grounded in the systems perspective. Quantifying and labelling 'pilot error' is archaic and provides misleading 'explanations' (Dekker, 2006). The SAW taxonomy is founded in the PCM which, as described in section 1.3, provides a more systemic and distributed approach and therefore has the potential to uncover the underlying processes involved in critical incident decision making. CERT has been previously described as an incident reporting tool using schematic organisers. The categories in CERT are very similar to those in the SAW taxonomy. However, issues arose with CERT in relation to its inflexibility and constraints placed on the recall of events. As a complement to the SAW taxonomy, the current authors 
have also developed the Schema-World-Action Research Method (SWARM) as an interview schedule for probing critical incidents (see Plant and Stanton, 2016). SWARM has tried to harness the dynamic nature of decision making, especially when viewed through the perspective of the PCM, and offers a semi-structured probing technique and could be applied to more flexibly structure narratives in incident reporting systems.

In relation to the further research opportunities offered by the development of the SAW taxonomy, it would be interesting to investigate if, and how, differences present themselves in the importance of SAW categories in difference scenarios (e.g. incidents/accidents, demographic differences, different types of incidents). For example, O'Hare (2006) found differences between pilots involved in incidents and accidents such that pilots who reported incident involvement, rather than accident involvement, characterised the event in terms of detection and diagnosis (i.e. earlier stage information processing) than did pilots who reported an accident event. A further line of enquiry is to investigate how these differences manifest with the SAW taxonomy. The SAW taxonomy also has the potential to complement existing methods. In a review of system-based accident analysis methods, Salmon et al. (2012) concluded that Accimaps, one of the most popular accident analysis methods, was limited by its lack of taxonomies at each descriptive level, for example it recognises flawed decisions but without identifying the factors that influence them. Salmon et al. (2012) also argued that the use of taxonomies facilitates the aggregation of data across multiple cases, this is consistent with Fleishman and Quaintance's (1984) assertion that taxonomy development allows for the establishment of a base for conducting and reporting research studies to facilitate their comparison. This is supported by the fact that in their review, Salmon et al. (2012) found the STAMP method, which is taxonomy based, provided a clearer understanding of why erroneous and inappropriate decisions were made. This was assisted by the fact that STAMP considers both the context in which decisions were made and how flawed mental models contribute to decisions; akin to the schema-world distinction in the SAW taxonomy. We are by no means claiming that the SAW taxonomy in its current form is an alternative accident analysis method. But the review by Salmon (2012) heighted the benefits of taxonomy based accident analysis methods and the gaps in existing methods. From this, there appears to be the potential for the SAW taxonomy to complement existing methods and this should certainly be an avenue for future research considerations.

\subsection{Evaluation}

Fleishman and Quaintance (1984:2) argued that 'in order to constitute a useful tool, a scientific classification must be founded inductively upon relationships that have a factual basis, i.e. relationships must be derived directly from the data'. The SAW taxonomy was data-driven using an inductive thematic analysis process to develop it as objectively as possible. However, as Braun and Clarke (2006) acknowledged, researchers can never fully free themselves from their theoretical perspectives. So whilst the SAW taxonomy is datadriven, it was still developed within the confines of the PCM and the data had already been deductively classified based on the high level categories of this model. Mitchell et al. (2014) conducted an extensive review of human factors taxonomies for use in a medical setting and found that a third of the taxonomies they reviewed did not have a theoretical model underpinning their development and that almost all of the taxonomies either focused on cognitive or contextual factors, rarely both. The SAW taxonomy was underpinned by a theory that considers both the contextual and cognitive factors of behaviour. Overall, the SAW taxonomy was developed with as little manipulation as possible and as Revell and Stanton (2012) argued, as long as biases are acknowledged then trust can be placed in the research output.

Fleishman and Quaintance (1984) defined three ways of evaluating classification systems. The first being internal validity, i.e. that the system is logical and parsimonious within itself. Within this they identified reliable descriptors, mutually exclusive classes, and exhaustive classifications as requirements of internal validity. The reliability assessment demonstrated that a reliable taxonomy has been produced and all of the 904 text segments were classified exclusively, i.e. a text segment was placed into only one category and every 
text segment was able to be classified. The second way to evaluate taxonomies is by establishing external validity, i.e. the taxonomy is capable of accomplishing its intended purpose. In this case that is increasing the explanatory power of the PCM by providing a more detailed understanding of the categories within this model and their role in decision making. The taxonomy needs to demonstrate usefulness as an aid in interpreting and integrating research results and establishing whether new data sets can be accurately assigned to the categories. Establishing external validity can only be achieved through subsequent research studies, ideally by other researchers to limit potential biases. The third way to evaluate taxonomies is the principle of utilitarian criterion or use rate, i.e. the taxonomy is actually used by researchers in the fields of interest. This can only be achieved through future research efforts, a potential barrier to achieving this is the aviation specific nature of the taxonomy. The SAW taxonomy is specific to understanding ACDM from the perspective of the PCM, this approach maximises specific utility of the method although this at the expense of generalizability to other problem domains (Fleishman and Quaintance, 1984). However, out of 28 categories only two categories make reference to aviation terminology: aviate and aircraft status. These could easily be supplemented by the domain under analysis as the descriptions for these categories are general enough to apply to any system interaction, particularly other transport domains. In domains other than aviation it may also be necessary to alter the category of standard operating procedures (potentially to rules or conventions).

We have previously identified the role of the perceptual cycle in ACDM (Plant and Stanton, 2013b; 2014a), but from this work we are able to explore the finer detail of the interactions. The results make intuitive sense, insomuch that concepts have the most relevance in the phases where they would expect to be found and are less relevant in phases where they are not expected. For example, decision action is the primary concept in the decision making phase, whereas severity of problem and concurrent diagnostics do not feature in the pre-incident phase (because the incident had not happened yet). For exploratory studies intuitive sense is important because it points towards the appropriateness of the data collection and analysis methods. The relative importance of concepts was objectively determined by the sociometric analysis function in Agna ${ }^{\mathrm{TM}}$ which suggests that the development of the SAW taxonomy and general classification method employed was appropriate for gaining an increased understanding about ACDM. Furthermore, the results are similar to those obtained by Schutte et al. (1996) who employed a different methodology, so it would suggest that a real phenomenon is described thus increasing confidence in the content validity of the taxonomy.

It is worth noting that the taxonomy was developed from data collected during retrospective recall and there are known limitations associated with this method. As highlighted by As chronicled by Ericsson and Simon (1980), the process of recalling an event is limited by the capacity of memory; only recently attended to information can be recalled from short term memory and information stored in long term memory can often be degraded and distorted (Bartlett, 1932). The semi-structured nature of the CDM interview schedule aims to limit some of these issues and a test-retest study has demonstrated accurate recall over a time elapse of more than two years (Plant and Stanton, 2013b), however how far the recalled information accurately represents the actual situation warrants more investigation and can only be achieved in combination with concurrent data collection methods, which is associated with a host of practical constraints, particularly in the context of aeronautical critical incidents.

\section{Concluding summary}

The decision making process is a significant and important aspect of successful flight deck operations. Understanding this can yield improved decision making strategies used by pilots and potentially reduce inappropriate decision making as well as their negative consequences. We have shown that different elements of the perceptual cycle differ in their importance depending on the phase of dealing with a critical incident. Understanding what information is utilised, when it is utilised, and how this interacts with actions undertaken is taking a step towards being able to develop more informative incident reporting systems, decision centred 
training aids, or design solutions based on the principles of perceptual cycle information processing. The PCM and the associated Schema Theory is capable of providing domainindependent insights in systems interactions (Plant and Stanton, 2013b). The PCM, with its description of the reciprocal relationship that exists between the mind and the environment, bridges the gap between ecological and information processing theories of behaviour. For the PCM to realise its potential research efforts need to focus on theoretical development and associated methods. The work presented here in the development of the SAW taxonomy has begun to address this and future research endeavours have been identified in order to continue this journey.

\section{Acknowledgements}

The authors thank the pilots who gave their time to participant in our interviews.

\section{References}

Baber, C., Stanton, N.A., Atkinson, J., McMaster, R. \& Houghton, R.J. 2013. Using social network analysis and agent-based modelling to explore information flow using common operational pictures for maritime search and rescue operations. Ergonomics, 56(6), 889-905

Beaubien, J. M., \& Baker, D.P. 2002. A review of selected aviation Human Factors taxonomies, accident/incident reporting systems, and data reporting tools. International Journal of Applied Aviation Studies, 2(2), 11-36.

Braun, V. \& Clarke, V. 2006. Using thematic analysis in psychology. Qualitative Research in Psychology, 3(2), 77-101

Boyatzis, R. E. 1998. Transforming Qualitative Information: Thematic Analysis and code development, Thousand Oaks, CA: Sage.

Burla, L., B. Knierim, J. Barth, K. Liewald, M. Duetz, and T. Abel. 2008. "From Text to Codings. Intercoder Reliability Assessment in Qualitative Content Analysis.” Nursing Research 57 (2): 113-117.

Civil Aviation Authority. 1997. CAP 667: Review of general aviation fatal accidents 19851994. London: Civil Aviation Authoriyu (UK).

Cohen-Hatten, S. R., Butler, P.C. \& Honey, R.C. An investigation of operational decision making in situ: incident command in the UK Fire and Rescue Service. Human Factors, 57(5), 793-804.

Cooke, D.L. \& Rohleder, T.R. 2006. Learning from incidents: from normal accidents to high reliability. System Dynamics Review, 22, 213-239.

Crandall, B. Klein, G.A. \& Hoffman, R.R. 2006. Working minds: A practitioner's guide to cognitive task analysis. Cambridge, MA: MIT Press.

Dekker, S. W. A. 2006. The field guide to understanding human error, Aldershot: Ashgate. 
Dekker, S.W. A. 2011. What is rational about killing a patient with an overdose? Enlightement, Continental Philosophy and the Role of the Human Subject in System Failure. Ergonomics, 54(8), 679-683.

Fleishman, E.A. \& Quaintance, M. K. 1984. Taxonomies of Human Performance. The Description of Human Tasks. Academic Press: Orlando, Fl.

Griffin, T.G.C., Young, M.A. \& Stanton, N.A. 2015. Human Factors Models for Aviation Accident Analysis and Prevention. Aldershot: Ashgate.

Hancock, P.A. \& Diaz, D.D. 2002. Ergonomics as a foundation for a science of purpose. Theoretical Issues in Ergonomics Science, 3(2), 115-123.

Harris, D. \& Stanton, N.A. 2010. Editorial: Aviation as a system of systems: Preface to the special issue of human factors in aviation. Ergonomics, 53 (2), 145-148.

Houghton, R.T., Baber, C., McMaster, R., Stanton, N.A., Salmon, P.M., Stewart, R. \& Walker, G. 2006. Command and control in emergency services operations: a social network analysis. Ergonomics, 49(12-13), 1204-1225.

Hutchins, E. 1995. Cognition in the Wild. MIT Press

Jarvis, S. \& Harris, D. 2010. Development of a bespoke human factors taxonomy for gliding accident analysis and its revelations about highly inexperienced UK glider pilots. Ergonomics, 53(2), 294-303.

Klein, G. A., and A. Armstrong. 2005. “Critical Decision Method.” In Handbook of Human Factors and Ergonomics Methods, edited by N. A. Stanton, A. Hedge, K. Brookhuis, E. Salas, and H. Hendrick, 35.1-35.8. Boca Raton, FL: CRC Press.

Klein, G. A., Calderwood, R. \& Macgregor, D. 1989. Critical Decision Method for Eliciting Knowledge. IEEE Transactions on Systems, Man and Cybernetics, 19 (3), 462-472.

Lipshitz, R., Klein, G., Orasanu, J. \& Salas, E. 2001. Focus Article: Taking stock of Naturalistic Decision Making. Journal of Behavioural Decision Making, 14, 331-352.

Lombard, M., J. Snyder-Duch, and C. C. Bracken. 2002. "Content Analysis in Mass Communication. Assessment and Reporting of Intercoder Reliability.” Human Communication Research 28 (4): 587-604.

Marques, J. F., and C. McCall. 2005. "The Application of Inter-Rater Reliability as a Solidification Instrument in a Phenomenological Study.” The Qualitative Report 10 (3): 439-462.

Militello, L.G. \& Hutton, R.J.B. 1998. Applied cognitive task analysis (ACTA): a practitioner's toolkit for understanding cognitive task demands. Ergonomics, 41(11), 1618-1641.

Mitchell, R.J., Williamson, A.m., Molesworth, B. \& Chung, A.Z.Q. 2014. A review of the use of human factors classification frameworks that identify causal factors for adverse events in the hospital setting. Ergonomics, 57(10), 1443-1472

Moir, Su., Paquet, V., Punnett, L., Buchholz, B. \& Wegman, D. 2003. Making Sense of Highway Construction: A Taxanomic Framework for Ergonomic Exposure Assessment and Intervention Research. Applied Occupational and Environmental Hygiene, 18(4), 256-267.

Neisser, U. 1976. Cognition and Reality. San Francisco: W.H.Freemand and Co

O'Hare, D. 1992. The ARTFUL decision maker: A framework model for aeronautical decision making. The International Journal of Aviation Psychology, 2(3), 175-191.

O’Hare, 2000. The 'Wheel of Misfortune': a taxonomic approach to human factors in accident investigation and analysis in aviation and other complex systems. Ergonomics, 43(12), 2001-2009.

O'Hare, D. 2006. Cognitive Functions and Performance Shaping Factors in Aviation Accidents and Incidents. The International Journal of Aviation Psychology, 16:2, 145-156.

O’Hare, D., Wiggins, M., Batt, R. \& Morrison, D. 1994. Cognitive failure analysis for aircraft accident investigation. Ergonomics, 37(11), 1855-1869 
O’Hare, D., Wiggins, M., Williams, A. \& Wong, W. 1998. Cognitive task analysis for design centred design and training. Ergonomics, 41(11), 1698-1718.

Orasanu, J. \& Connolly, T. 1993. The reinvention of decision making, in Decision Making in Action: Models and Methods, G.A. Klein and J. Orasanu, R. Calderwood and C. Zsambok (Eds). Norwood, CT: Ablex.

Orasanu, J. \& Martin, L. Errors in aviation decision making: a factor in accidents and incidents. In Proceedings of the second workshop on human error, safety and system development, April 1-2 1998. Seattle, WA.

Patton, M.Q. 1990. Qualitative evaluation and research methods, $2^{\text {nd }}$ ed. Newbury Park, CA: Sage:

Plant, K.L. \& Stanton, N.A. 2011. A critical incident in the cockpit: Analysis of a critical incident interview using the Leximancer ${ }^{\mathrm{TM}}$ tool. In Proceedings of the $3^{\text {rd }}$ International Conference of the European Aerospace Societies. 24-28 ${ }^{\text {th }}$ October 2001, Venice, Italy

Plant, K.L. \& Stanton, N.A. 2012a. Why did the pilots shut down the wrong engine? Explaining errors in context using Schema Theory and the Perceptual Cycle Model. Safety Science, 50, 300-315.

Plant, K. L., \& Stanton, N. A. 2012b. "I did something against all regulations”: Decision making in critical incidents. In Proceedings of the $4^{\text {th }}$ International Conference on Applied Human Factors and Ergonomics, 21-25 ${ }^{\text {th }}$ July 2012, San Francisco, America. Conference book: Advances in Human Aspects of Aviation (2012). Landry, S (Ed). CRC Press.

Plant, K.L. \& Stanton, N.A. 2013a. What's on your mind? Using the Perceptual Cycle Model and Critical Decision Method to understand the decision-making process in the cockpit. Ergonomics, 56(8), 1232-1250.

Plant, K.L. \& Stanton, N.A. 2013b. The explanatory power of Schema Theory: Theoretical foundations and future applications in Ergonomics. Ergonomics, 56(1), 1-15.

Plant, K.L. \& Stanton, N.A. 2014a. The process of processing: exploring the validity of Neisser's perceptual cycle with accounts from critical decision-making in the cockpit. Ergonomics, DOI: 10.1080/00140139.2014.991765

Plant, K.L. \& Stanton, N.A. 2014b. All for one and one for all: Representing teams as a collection of individuals and an individual collective using a network perceptual cycle approach. International Journal of Industrial Ergonomics, 44, 777-792.

Plant, K.L. \& Stanton, N.A. 2016. The development of the Schema-World-Action Research Method (SWARM) for the elicitation of Perceptual Cycle data. Theoretical Issues in Ergonomics Science, 17(4), 376-401.

Rasmussen, J. 1983. Skills, Rules, and Knowledge; signals, signs, and symbols, and other distinctions in human performance models. IEEE Transactions on Systems, Man and Cybernetics, 13(3), 257-266.

Reason, J. 1990. Human Error. Cambridge: Cambridge University Press.

Revell, K. \& Stanton, N.A. 2012. Models of models: filtering and bias rings in depiction of knowledge. Ergonomics, 55(9), 1073-1092.

Rodrigues de Carvalho, P.V., Gomes, J.O., Huber, G.J. \& Vidal, M.C. 2009.Normal people working in normal organisations with normal equipments: system safety and cognition in a mid-air collisions. Applied Ergonomics, 40, 325-340

Salmon, P.M., Cornelissen, M. \& Trotter, M.J. 2012. Systems-based accident analysis methods: A comparison of Accimap, HFACS, and STAMP. Safety Science, 50, 1158-1170.

Salmon, P.M., Lenne, M.G., Walker, G.H., Stanton, N.A. \& Filtness, A. 2014. Exploring schema-driven differences in situation awareness between road users: an on-road study of driver, cyclist and motorcyclist situation awareness. Ergonomics, 57(2), 191209.

Salmon, P.M., Read, G.J.M., Stanton, N.A. \& Lenne, M.G. 2013. The crash at Kerang: Investigating systemic and psychological factors leading to unintentional noncompliance at rail level crossings. Accident Analysis and Prevention, 50, 1278-1288. 
Sarter, N.B. \& Alexander, H.M. 2000. Error types and related error detection mechanisms in the aviation domain: An analysis of aviation safety reporting system incident reports. The International Journal of Aviation Psychology, 10:2, 189-206.

Schutte, P.C. \& Trujillo, A.C. 1996. Flight crew task management in non-normal situations. Proceedings of the 40th Annual Meeting of the Human Factors and Ergonomics Society, pp. 244-248. Santa Monica, CA: HFES.

Simpson, P.A. 2001. Naturalistic Decision Making in Aviation Environments. Report No. DSTO-GD-0279. DSTO Aeronautical and Maritime Research Laboratory, Australia.

Stanton, N.A. 2013. Representing distributed cognition in complex systems: How a submarine returns to periscope depth. Ergonomics, 57(3), 403-418.

Stanton, N.A. \& Salmon, P.M. 2009. Human error taxonomies applied to driving: A generic driver error taxonomy and its implications for intelligent transport systems. Safety Science, 47, 227-237.

Stanton, N.A. \& Walker, G.H. 2011. Exploring the psychological factors involved in the Ladbroke Grove rail accident. Accident Analysis and Prevention, 43(3), 1117-1127

Stanton, N. A., Salmon, P. M., Rafferty, L.A., Walker, G. H., Baber, C. \& Jenkins, D. 2013. Human Factor Methods. A Practical Guide for Engineering and Design, ${ }^{\text {nd }}$ ed. Aldershot: Ashgate.

Walker, G. H. 2005. Verbal Protocol Analysis. In: Stanton, N. A., Hedge, A., Brookhuis, K., Salas, E. \& Hendrick, H., eds. Handbook of Human Factors and Ergonomics Methods. Boca Raton, FL: CRC Press, 30.1-30.8

Walker, G.H., Stanton, N.A., Baber, C., Wells, L., Gibson, H., Salmon, P.M. \& Jenkins, D. 2010. From ethnography to the EAST method: A tractable approach for representing distributed cognition in Air Traffic Control. Ergonomics, 53 (2), 184-197.

Walker, G. H., Stanton, N. A. \& Salmon, P. M. 2011. Cognitive compatibility of motorcyclists and car drivers. Accident Analysis and Prevention, 43, 878-888.

Wiegmann, D.A. \& von Thaden, T.L. 2003. Using schematic aids to improve recall in incident reporting: The Critical Event Reporting Tool (CERT). The International Journla of Aviation Psychology, 13(2), 153-171. 
Table 1. Schema subtypes (theme name, description, examples and percentage of data within in category)

\begin{tabular}{|c|c|c|c|}
\hline Schema subtype & Description & Examples & $\begin{array}{l}\text { Data } \\
\text { (percentage) }\end{array}$ \\
\hline $\begin{array}{l}\text { Vicarious past } \\
\text { experience (VPE) }\end{array}$ & $\begin{array}{l}\text { Statements relating to experiencing something in the } \\
\text { imagination through the description by another person (e.g. } \\
\text { hearing a colleague recall an incident they were involved } \\
\text { with) or documentation (e.g. reading about a certain event in } \\
\text { an industry magazine or incident/accident report). }\end{array}$ & $\begin{array}{l}\text { "I knew I had surged the engine...I had heard about surging...I } \\
\text { hadn't experienced it but I knew that the engine was surging. It } \\
\text { had been described to me, in books. You don't train for it. No one } \\
\text { plays you a sound clip, it's more by reading documents I } \\
\text { suppose" }\end{array}$ & $5 \%$ \\
\hline $\begin{array}{l}\text { Direct past } \\
\text { experience (DPE) }\end{array}$ & $\begin{array}{l}\text { Statements relating to direct personal experience of similar } \\
\text { events or situations in the past. This covers events } \\
\text { experienced in live, operational contexts as opposed to those } \\
\text { experienced through training. }\end{array}$ & $\begin{array}{l}\text { "I have experienced levels of vibration on other aircraft and I } \\
\text { know what is normal, what is abnormal, this exceeded it } \\
\text { tenfold..." }\end{array}$ & $26 \%$ \\
\hline $\begin{array}{l}\text { Trained past } \\
\text { experience (TPE) }\end{array}$ & $\begin{array}{l}\text { Statements relating to knowledge developed by direct } \\
\text { personal experience of a specific task, event or situation, } \\
\text { experienced within the confines of a training scenario (e.g. } \\
\text { ground school training, simulator training or training sorties) }\end{array}$ & $\begin{array}{l}\text { "The decision of what to do was in my experience because of } \\
\text { training. I had seen this instance before in a simulator" }\end{array}$ & $25 \%$ \\
\hline $\begin{array}{l}\text { Declarative schema } \\
\text { (DS) }\end{array}$ & $\begin{array}{l}\text { Statements relating to a schema that manifests as a descriptive } \\
\text { knowledge of facts, usually as a product of the world } \\
\text { information available }\end{array}$ & $\begin{array}{l}\text { "I knew it had just come out of maintenance, I was aware it could } \\
\text { be a spurious event" }\end{array}$ & $24 \%$ \\
\hline $\begin{array}{l}\text { Analogical schema } \\
\text { (AS) }\end{array}$ & $\begin{array}{l}\text { Statements relating to comparisons between things for the } \\
\text { purpose of explanation and clarification. Typically these } \\
\text { analogies will be structural analogies of physical objects or } \\
\text { states of affairs in the world (akin to mental map or mental } \\
\text { model) }\end{array}$ & $\begin{array}{l}\text { "How high am I, how fast am I, can't see a lot so having to make } \\
\text { this picture in my head based on the information that I do know" }\end{array}$ & $3 \%$ \\
\hline $\begin{array}{l}\text { Insufficient schema } \\
\text { (IS) }\end{array}$ & $\begin{array}{l}\text { Statements relating to inadequate or lacking knowledge, i.e. a } \\
\text { schema is not developed for a certain situation }\end{array}$ & $\begin{array}{l}\text { "It didn't fail like they do in training, so I wasn't instantly sure it } \\
\text { was an engine failure" }\end{array}$ & $17 \%$ \\
\hline
\end{tabular}


Table 2. Action subtypes (theme name, description, examples and percentage of data within in category)

\begin{tabular}{|c|c|c|c|}
\hline Action subtype & Description & Examples & $\begin{array}{l}\text { Data } \\
\text { (percentage) }\end{array}$ \\
\hline Aviate (Av) & $\begin{array}{l}\text { Statements relating to direct manipulation (handling) of } \\
\text { flight controls in order that the aircraft can be flown and } \\
\text { safety is maintained }\end{array}$ & "I attempted to roll the aircraft level" & $23 \%$ \\
\hline Navigate (Nav) & $\begin{array}{l}\text { Statements relating to the process of accurately ascertaining } \\
\text { position and planning and following a route or desired course }\end{array}$ & "I followed the coast back" & $2 \%$ \\
\hline $\begin{array}{l}\text { Communicate } \\
\text { (Comm) }\end{array}$ & Statements relating to the sharing or exchange of information & "I transmitted a non-standard mayday call" & $9 \%$ \\
\hline $\begin{array}{l}\text { System management } \\
\text { (Sys Man) }\end{array}$ & $\begin{array}{l}\text { Statements relating to the processes of making an input into } \\
\text { technological systems in order that the interaction or } \\
\text { manipulation has an explicit output }\end{array}$ & $\begin{array}{l}\text { "I put in St. Albans head into the navigation system, So I typed } \\
\text { in the three digit code which is St. Albans head" }\end{array}$ & $7 \%$ \\
\hline $\begin{array}{l}\text { System monitoring } \\
\text { (Sys Mon) }\end{array}$ & $\begin{array}{l}\text { Statements relating to looking at (observing, checking) } \\
\text { displays to gain an understanding of the situation }\end{array}$ & "I did a complete scan of all the systems information" & $10 \%$ \\
\hline $\begin{array}{l}\text { Environment } \\
\text { monitoring (Env } \\
\text { Mon) }\end{array}$ & $\begin{array}{l}\text { Statements relating to observing or checking the internal or } \\
\text { external physical environment in order to establish the } \\
\text { current state-of-affairs }\end{array}$ & $\begin{array}{l}\text { "I was keeping eyes out for ground contact and searching for } \\
\text { visual references" }\end{array}$ & $4 \%$ \\
\hline $\begin{array}{l}\text { Concurrent diagnostic } \\
\text { action (Conc Diag) }\end{array}$ & $\begin{array}{l}\text { Statements relating to the process of determining, or } \\
\text { attempting to determine, the cause or nature of a problem by } \\
\text { examining the available information at the time the incident } \\
\text { is occurring }\end{array}$ & $\begin{array}{l}\text { "We initially started looking for circuit breakers, to look if any } \\
\text { had popped" }\end{array}$ & $6 \%$ \\
\hline Decision action (DA) & $\begin{array}{l}\text { Statements relating to a conclusion or resolution that is } \\
\text { reached after considering the available information }\end{array}$ & $\begin{array}{l}\text { "The first decision was to idle back the bad engine, rather than } \\
\text { shut it down" }\end{array}$ & $16 \%$ \\
\hline $\begin{array}{l}\text { Situation assessment } \\
\text { (Sit Ass) }\end{array}$ & $\begin{array}{l}\text { Statements relating to actions that relate to the evaluation } \\
\text { and interpretation of available information }\end{array}$ & $\begin{array}{l}\text { "Trying to take into account the threats to you and the aircraft, } \\
\text { i.e. if I precede down a given path what is it likely to result in?" }\end{array}$ & $8 \%$ \\
\hline Non-action (Non A) & $\begin{array}{l}\text { Statements relating to actions that were not performed, either } \\
\text { because the situation didn't warrant a particular action or }\end{array}$ & "I couldn't read any of the instruments or communicate" & $5 \%$ \\
\hline
\end{tabular}


because equipment faults did not allow a particular action to

be performed or because the pilot made an error or omission.

Standard Operating Statements relating to following the prescribed procedure

that ought to be routinely followed in a given situation 
Table 3. World subtypes (theme name, description, examples and percentage of data within in category)

\begin{tabular}{|c|c|c|c|}
\hline World subtype & Description & Examples & Data \\
\hline $\begin{array}{l}\text { Natural environmental } \\
\text { conditions (NEC) }\end{array}$ & $\begin{array}{l}\text { Statements about natural environmental conditions (e.g. weather, light, } \\
\text { temperature, noise) }\end{array}$ & "Fortunately it was a clear day, nice sunny day" & $14 \%$ \\
\hline $\begin{array}{l}\text { Technological } \\
\text { conditions (Tech Cond) }\end{array}$ & $\begin{array}{l}\text { Statements relating to the state of technological artefacts (e.g. with regards } \\
\text { to appearance and working order) }\end{array}$ & “...engines responded and all other stuff came back on” & $8 \%$ \\
\hline $\begin{array}{l}\text { Communicated } \\
\text { information (Comm } \\
\text { info) }\end{array}$ & $\begin{array}{l}\text { Statements relating to information available to the pilot from other people } \\
\text { (e.g. other crew members, ATC, coastguard etc.) }\end{array}$ & "I received the cloud base report from Newquay" & $5 \%$ \\
\hline Location (Loc) & Statements relating to particular places or positions & “...so now we were over the destination” & $14 \%$ \\
\hline Artefacts (Art) & $\begin{array}{l}\text { Statements discussing physical objects, including written information, } \\
\text { symbols, diagrams or equipment }\end{array}$ & "I had the flight reference cards" & $5 \%$ \\
\hline $\begin{array}{l}\text { Display indications (Dis } \\
\text { Ind) }\end{array}$ & Statements relating to the information elicited from the physical artefacts & $\begin{array}{l}\text { "Only thing identifiable was the high transmission oil } \\
\text { temperature" }\end{array}$ & $12 \%$ \\
\hline $\begin{array}{l}\text { Operational context (Op } \\
\text { Cont) }\end{array}$ & $\begin{array}{l}\text { Statements relating to the routine functions or activities of the organisation } \\
\text { (e.g. Search and Rescue, Police search, military training etc.). This can } \\
\text { include statements about the importance of being serviceable for the } \\
\text { operational context or crew familiarity with the aircraft and how this } \\
\text { effects decision making. }\end{array}$ & $\begin{array}{l}\text { "the aircraft was relatively heavy because we were } \\
\text { taking people back to Germany" }\end{array}$ & $14 \%$ \\
\hline Aircraft status (Air Stat) & $\begin{array}{l}\text { Statements relating to the current status of the aircraft's integrity or } \\
\text { performance (e.g. how good or bad it is flying, the current configuration of } \\
\text { the aircraft, autopilot activation etc.) }\end{array}$ & "the aircraft was flying fine" & $7 \%$ \\
\hline Severity of problem & Statements relating to how bad (or otherwise) the critical incident is & "we weren’t in any immediate danger" & $3 \%$ \\
\hline
\end{tabular}


Physical cues (Phys

Cue)

Absent information (Abs Info)
Statements relating to external cues that provide information of conditions or states of being (e.g. noises, sounds, vibration, smells)

"there was a loud bang, coughing and spluttering"

Statements relating to information that was missing, not present or lacking.

"I didn't have a comprehensive map"

$8 \%$ existent information 
Table 4. Matrix showing the relative importance of the SAW concepts in each phase of dealing with a critical incident (numbers denote order of importance for primary and secondary concepts based on calculation from sociometric status)

\begin{tabular}{|c|c|c|c|c|}
\hline \multicolumn{2}{|r|}{ Primary concept } & Secondary concept & Tertiary concept & \\
\hline
\end{tabular}

\begin{tabular}{|c|c|c|c|c|c|c|c|}
\hline & & \multicolumn{6}{|c|}{ Phase of incident } \\
\hline PCM & SAW taxonomy & Pre-incident & Onset of problem & Immediate actions & Decision making & Subsequent actions & Incident containmen \\
\hline \multirow{6}{*}{ Schema } & Vicarious past experience & & & & & & \\
\hline & Direct past experience & & 5 & 5 & 4 & 8 & \\
\hline & Trained past experience & & 6 & 2 & 7 & 11 & \\
\hline & Declarative schema & 6 & & & 9 & 3 & \\
\hline & Analogical schema & & & & & & \\
\hline & Insufficient schema & & $\overline{11}$ & 11 & & 9 & \\
\hline \multirow{11}{*}{ Action } & Aviate & 4 & 3 & 3 & 10 & 1 & 1 \\
\hline & Navigate & & & & & & \\
\hline & Communicate & & & 8 & 6 & 4 & 5 \\
\hline & System management & & 12 & & & & 4 \\
\hline & System monitoring & & 8 & 4 & & & \\
\hline & Environment monitoring & & & & & $\overline{10}$ & \\
\hline & Concurrent diagnostics & & 9 & 6 & & & \\
\hline & Decision action & & & 7 & 1 & 2 & \\
\hline & Situation assessment & & & 9 & 3 & & \\
\hline & Non-action & & & 12 & & & \\
\hline & SOP & 5 & & 10 & 12 & & \\
\hline \multirow{7}{*}{ World } & Natural Environment & 1 & 7 & & & 6 & \\
\hline & Technological conditions & & 2 & & & & \\
\hline & $\begin{array}{l}\text { Communicated } \\
\text { information }\end{array}$ & & & & & & \\
\hline & Location & 3 & & & 2 & 12 & 2 \\
\hline & Artefacts & & & 13 & & & \\
\hline & Display indications & & 4 & 1 & 11 & 5 & \\
\hline & Operational context & 2 & & & & 13 & 3 \\
\hline
\end{tabular}




\begin{tabular}{|l|l|c|c|c|c|c|}
\hline \multirow{2}{*}{} & Aircraft status & & & & 5 & \\
\cline { 2 - 6 } & Severity of problem & & & & \\
\cline { 2 - 6 } & Physical cues & 7 & 1 & 14 & & \\
\cline { 2 - 7 } & Absent information & & 10 & & 8 & \\
\hline
\end{tabular}


